\title{
Levantamento teórico sobre as causas dos insucessos das tentativas de reforma administrativa
}

Revista do

Serviço

Público

Ano 54

Número 3

Jul-Set 2003

Carlos Frederico Alverga

\section{Introdução}

As tentativas de reformar o Estado brasileiro foram objetos de estudos de numerosos pesquisadores nacionais e estrangeiros, tais como Gilbert Siegel (1964), Lawrence Graham (1968), Beatriz Wahrlich (1983 e 1984), Gileno Marcelino (1989), Nelson Mello e Souza (1994), Luiz Alberto dos Santos (1997), Olavo Brasil de Lima Júnior (1998). De acordo com Ollaik (1999, p. 41-43), tais tentativas, quais sejam, a do Departamento Administrativo do Serviço Público (DASP), de 1938, a da Comissão Amaral Peixoto, de 1963, quando, no Governo João Goulart, foi criado o Ministério Extraordinário para a Reforma Administrativa, e a do DecretoLei no 200 , de 1967, falharam em atingir seus intentos, que eram, basicamente, relativos à promoção do fortalecimento da meritocracia no serviço público nacional. Além disso, Santos (1997, p. 45-49) nos informa que as reformas administrativas da Nova República (1986) e do Governo Collor (1990) também malograram. Ollaik (1999) tem sua argumentação confirmada por Bressan (Lamounier; Figueiredo, 2002, p. 387), que escreve:

"Ao determinar, por simples medida administrativa, o fim da politização na administração pública, o MARE (Ministério da Administração Federal e da Reforma do Estado) ignorou toda a história de fracasso das reformas anteriores. As mais importantes, inclusive, foram adotadas em momentos de grande "autoridade" do governo federal: a criação do Departamento Administrativo do Serviço Público (DASP), em 1938, em pleno Estado Novo; e o Decreto-Lei n⿳ํㅡㄹ 200, de 1967, durante a ditadura militar. Em nenhum

Carlos Frederico Alverga é mestre em Ciência Política pela UnB.

Contato: rubino68@ ig.com.br 
dos dois processos, o impulso reformador e modernizador do governo foi capaz de superar a tradição patrimonialista do nosso sistema político".

As análises antes enunciadas podem sugerir a existência de uma seqüência de insucessos das referidas tentativas, ou seja, de uma possível trajetória de fracassos. Um dos elementos causadores desses fracassos seria a questão da dependência da trajetória (path dependance).

Além disso, outros aspectos merecem consideração no processo de transformação institucional; no caso, as tentativas de reforma da administração pública brasileira. Esses aspectos podem ser, principalmente, de caráter organizacional e sociológico, no que se refere ao ambiente socioinstitucional no qual a tentativa de processo de mudança das instituições ocorre. No caso do aspecto organizacional, ele se refere a características das organizações que agiriam no sentido de dificultar a transformação destas. Os autores que servirão de base para a abordagem desse aspecto serão March e Olsen (1989) e North (1990). No caso da análise dos fatores sociológicos que influenciam o processo de transformação institucional, o argumento básico dessa abordagem é o de que, quando se pretende impor uma reforma institucional fundamentada em valores que não são referendados socialmente, em elementos que não são legitimados pela prática concreta da sociedade, o resultado desse processo será o malogro. Segundo Barbosa (1996, p. 59),

“A questão não é a existência de um sistema de meritocracia no serviço público brasileiro, mas, sim, a sua legitimidade na prática social. Ou melhor, a transformação deste sistema meritocrático existente no plano formal e no plano do discurso em uma prática social meritocrática".

Os autores que subsidiarão esta parte do trabalho serão Graham (1968), Mello e Souza (1994) e Barbosa (1996).

Outra maneira de examinar a questão da reforma administrativa e seu fracasso é encarando-a como um problema de ação coletiva, abordagem desenvolvida por Geddes (1994). Por essa ótica, existe incentivo para a desmobilização por parte daqueles que defendem a reforma, devido ao problema do carona (free-rider), dado que todos os cidadãos, indistintamente, se beneficiarão da reforma administrativa, tendo contribuído ou não para sua execução, e, ao mesmo tempo, existe estímulo para a mobilização por parte daqueles que se opõem à reestruturação, devido ao fato de seus privilégios estarem ameaçados. A consequiência dessa situação seria a não-implementação da referida reforma. Por fim, existe a explicação política para os insucessos das tentativas de reforma da administração pública, segundo a qual características do sistema político-eleitoral, 
bem como do padrão de barganha política entre a Presidência da República

e o Congresso, influenciam no malogro das tentativas de reforma da administração pública tanto no Brasil como em outros países, como, por exemplo, os Estados Unidos. Os autores que servirão de base para essa abordagem serão Geddes (1994), que analisa o modo pelo qual o sistema político-eleitoral brasileiro influencia negativamente a implementação das tentativas de reforma administrativa, e March e Olsen (1989), que examinam de que forma o relacionamento político, caracterizado pela barganha, entre a Presidência da República e o Congresso dos Estados Unidos, impede a efetivação da reestruturação da administração pública daquele país, fato esse que também pode ocorrer no Brasil, dificultando a execução da reforma administrativa em nosso país.

\section{A questão da dependência da trajetória}

O conceito de dependência da trajetória tem como idéia básica, segundo Pierson (2000, p. 252), o fato de referir-se "à relevância causal de estágios precedentes em uma seqüência temporal. William Sewel (1996, p. 262-263), por exemplo, sugere que dependência da trajetória significa que "o que aconteceu em um ponto anterior do tempo vai afetar os possíveis resultados da sequiência de eventos que acontecerão em um ponto no futuro". Ainda de acordo com Pierson (2000, p. 252), o problema dessa definição, de caráter mais geral, é que ela nos informa que "eventos anteriores em uma seqüência influenciam resultados e trajetórias, mas não necessariamente induzindo à ocorrência de movimentos futuros na mesma direção". Para sanar esse problema, será enunciada a definição mais específica de dependência da trajetória, de Margaret Levi (1997, apud Pierson, 2000, p. 252), para quem esse conceito significa que, "uma vez que um país ou região tenha começado determinada trilha, os custos de reversão são muito altos. Haverá outros pontos de escolha, mas o enraizamento de certos arranjos institucionais obstrui uma reversão fácil da escolha inicial". A definição a ser aqui adotada é a mais específica, por último enunciada. Entenda-se por "custos de reversão" aqueles custos relativos à mudança de trajetória institucional.

Outro autor que estudou o conceito de dependência da trajetória foi Douglass North (1990). Para ele, o referido conceito significa que, uma vez que o desenvolvimento da trajetória é estabelecido em determinado sentido, as externalidades em rede ${ }^{1}$, o processo de aprendizado das organizações $^{2}$ e os modelos subjetivos de percepção das questões públicas ${ }^{3}$, derivados historicamente, reforçam a direção de início adotada (North, 1990, p. 99). Outro ponto importante apontado por esse autor é a questão dos retornos crescentes. Segundo ele, "a sobrevivência tenaz de restrições 
institucionais em face de alterações radicais das regras formais do jogo é a melhor evidência das características de retornos crescentes de estrutura institucional" (Ibidem, p. 101). O conceito de retornos crescentes é abordado também por Pierson (2000):

"Cada ponto ao longo de uma trajetória particular produz consequiências que fazem essa trajetória mais atraente para o próximo período. À medida que esses efeitos começam a se acumular, eles geram um poderoso círculo virtuoso (ou vicioso) de atividade autoreforçada. (...) Com retornos crescentes, os atores têm incentivos fortes para se concentrar em única alternativa e continuar trilhando trajetória específica, uma vez que os passos iniciais tenham sido dados nessa direção" (Pierson, 2000, p. 253-254).

Além disso, reforçando o argumento de North, Pierson nos informa que "Instituições existentes geram poderosos incentivos que reforçam sua própria estabilidade e desenvolvimento posterior" (Pierson, 2000, p. 255). Pode-se considerar que os "incentivos" (benefícios auferidos pelos atores sociais, políticos e burocratas, principalmente, que atuam em contextos institucionais definidos) a que Pierson se refere sejam os retornos crescentes antes mencionados, que exercem influência na estabilidade, na "rigidez" das instituições. Ou seja, os citados atores sociais, ao serem favorecidos pelos arranjos institucionais em vigor, tenderiam a reforçar a continuidade da vigência da trajetória institucional na qual operam.

Um exemplo concreto do conceito de dependência da trajetória é o presente no seguinte trecho de North (1990, p. 102): “A evolução da América do Norte e da América Latina foi radicalmente diferente desde o início, refletindo a imposição de padrões institucionais da pátria mãe às suas colônias e as construções ideológicas radicalmente divergentes que moldaram as percepções dos atores". Uma consequiência real da situação de dependência da trajetória também nos é informada pelo mesmo autor (Ibidem, p. 103), quando ele escreve que, apesar das antigas colônias espanholas, ao se tornarem independentes, terem adotado constituições inspiradas na dos Estados Unidos, os resultados obtidos foram radicalmente distintos. Tal situação pode, segundo North, ser atribuída a padrões diferentes da evolução institucional desses países, que refletem, por sua vez, a natureza diversa das organizações institucionais de suas antigas metrópoles coloniais, Espanha e Inglaterra, respectivamente.

March e Olsen (1989) também abordam a questão da dependência da trajetória, só que a denominam de "armadilha da competência". Eles escrevem:

"Na situação típica, a eficiência crescente de uma tecnologia particular aumenta com sua utilização, a qual depois aumenta ainda 
mais a eficiência. O sistema tende a ficar muito eficiente na tecnologia que está sendo usada, e esta eficiência reforça a probabilidade de usar a referida tecnologia. $\mathrm{O}$ processo é totalmente sensato, dado que ele conduz a um nível de eficiência com tecnologia subótima que seja alta o bastante para fazer esta tecnologia preferível no curto prazo a uma tecnologia melhor, com a qual o sistema tem menos experiência e é menos eficiente" (March e Olsen, 1989, p. 63).

Ou seja, os agentes já estão tão familiarizados com a tecnologia menos eficiente que preferem continuar utilizando-a a adotar outra tecnologia nova mais eficiente, com a qual não estão habituados. A idéia é aplicar este argumento, que originalmente serviu para o estudo da tecnologia na economia, à análise da questão da mudança institucional.

Aplicando o conceito de dependência da trajetória à sucessão de fracassos das tentativas de reforma da administração pública brasileira no século XX, que nos é informada por Ollaik (1999, p. 41-43), pode-se cogitar a hipótese de que as estruturas administrativas brasileiras, caracterizadas pela presença do patrimonialismo e do clientelismo político, segundo Lima Júnior (1998, p. 18), podem ter se transformado em arranjos institucionais extremamente enraizados no interior do Estado nacional, e este fator, conjugado com os retornos crescentes que os referidos arranjos institucionais proporcionam aos atores sociais que neles atuam, pode ter contribuído para tornar extremamente elevado o custo de execução de reforma administrativa em nosso país, dificultando, assim, a reversão da trajetória institucional do Estado nacional, patrimonialista e clientelista conforme mencionado anteriormente. O referido custo seria o "custo de reversão". Em outras palavras, uma possível explicação para os referidos malogros nas ocasiões em que se tentou reformar a administração pública brasileira, pode ser o fato de que, dado que o Brasil iniciou uma trajetória administrativa caracterizada pela presença do patrimonialismo e do clientelismo político (Lima Júnior,1998), os “custos de reversão" desse caminho, segundo a definição de dependência da trajetória de Margaret Levi anteriormente citada, podem ter se tornado muito significativos, o que explicaria, em parte, a falta de êxito das tentativas de reforma do Estado brasileiro no século XX. Além disso, os retornos crescentes poderiam interferir nesse processo na medida em que os atores institucionais, já tendo conhecimento de como agir num contexto administrativo patrimonialista e clientelista e tendo desenvolvido estratégias de atuação para operar nesse ambiente, tenderiam a reforçar o caminho de início trilhado e resistir à mudança e à reforma do Estado nacional. $\mathrm{Ou}$ seja, em caso de a aludida reestruturação ocorrer, os citados atores teriam de aprender a operar em nova realidade institucional, diferente da anterior, o que implicaria custos para eles. 

do New handbook of Political Science, da Universidade de Oxford, no qual Goodin e Kingerman (1998, p. 152), ao se referirem à questão da estabilidade institucional, nos informam que

"A abordagem econômica analisa as instituições como pontos de equilíbrio que são duradouros, em primeira instância, porque ninguém tem interesse em mudá-las. Elas são, nesse sentido, autoreforçáveis. (...) Tanto foi investido pelos atores no aprendizado sobre como operar em um arranjo institucional conhecido que, apesar de haver soluções teoricamente mais eficientes, os custos de aprendizagem inviabilizariam a mudança".

\section{A abordagem organizacional}

A abordagem organizacional nos informa que as organizações são "grupos de indivíduos dedicados a alguma atividade executada com determinado fim" (North, 1992, p. 11). O mesmo autor (Ibidem, p.11) também afirma que o contexto institucional impõe restrições ao funcionamento das organizações, determinando os tipos de organizações que serão criadas. March e Olsen (1989) afirmam que, nos Estados Unidos, assim como no Brasil, as tentativas de modificar intencionalmente a administração pública têm fracassado. Os referidos autores apontam como um dos possíveis motivos para esses malogros o fato de, nas instituições políticas complexas, no caso a administração pública, que pode ser considerada uma organização, de acordo com a definição de North anteriormente transcrita, existirem três tipos de atores envolvidos no processo de mudança: os indivíduos que operam nas instituições, as próprias instituições, e o conjunto de outras instituições, que pode ser chamado de ambiente institucional. As dificuldades de modificar as instituições decorrem do fato de que, muitas vezes, ocorrem conflitos irreconciliáveis de objetivos entre indivíduos, instituições e ambiente institucional. Nada garante que os objetivos dos três sejam consistentes entre si (March; Olsen, 1989, p. 56-57). Esses autores analisam as tentativas de reorganização compreensiva da administração pública americana, considerando que tais tentativas consistem em promover modificações globais e feitas de uma só vez em todo o sistema administrativo do Estado. Essa idéia se opõe à de mudança institucional incremental, gradativa, defendida por Charles Lindblom. Os referidos autores arrolam como causas para os malogros das tentativas de reorganização compreensiva o fato de ser muito difícil manter a atenção dos principais atores políticos em relação à reforma e o caráter de "lata de lixo" das reorganizações administrativas, pelo qual elas passam a ser 
vinculadas a uma série de idéias sem nenhuma relação com suas reais intenções iniciais, de modo que as referidas idéias poderiam, então, ser jogadas na "lata de lixo", e não fariam falta nenhuma. Em relação a esse assunto, os referidos autores escrevem que "o curso dos eventos referentes à reorganização parecem depender menos das propriedades das propostas ou esforços da reorganização em si do que do curso da atenção política de curto prazo, sobre os quais os comitês de reorganização têm pouco controle"(March; Olsen; 1989, p. 81). Mais especificamente sobre a questão da atenção, eles afirmam que "os esforços de reorganização têm dificuldade em manter a atenção dos atores políticos principais. (...) Presidentes, líderes congressuais, os grupos de interesse mais importantes, servidores civis da alta administração pública são muito ocupados para serem mais do que participantes ocasionais" (Ibidem, p. 81). Ou seja, a atenção é recurso escasso, e dada a multiplicidade de tarefas dos atores políticos principais que agem na reorganização administrativa, eles têm pouco tempo para se dedicar à sua implementação. Como exemplo disso, os autores citados mencionam o caso da atenção do presidente americano. Escrevem eles: “A história com respeito à atenção presidencial é clara. Apesar de ser difícil prever qual crise específica, escândalo ou guerra irá desviar a atenção presidencial e dos outros adeptos da reorganização da implementação da mesma, é fácil prever que alguma coisa irá" (March; Olsen; 1989). Os aludidos autores citam os exemplos de Woodrow Wilson, que teve sua atenção desviada de seus princípios administrativos pela Primeira Grande Guerra, e de Roosevelt, que teve sua atenção desviada continuamente de seus planos de reorganização devido a necessidades imediatas (Ibidem, p. 81). Além disso, os mencionados autores argumentam que "mudanças resultantes de esforços em reorganizações compreensivas parecem pequenas, comparadas a modificações produzidas por transformação contínua e incremental" (Ibidem, 85). Esse argumento vai ao encontro da proposição de North (1990), no sentido de que as alterações nas instituições ocorrem de modo incremental e contínuo (pequenas modificações ao longo do tempo). North (1990, p. 89) escreve que "O ponto mais importante sobre mudança institucional (...) é que mudança institucional é predominantemente incremental". Isso significa que, para os referidos autores, as tentativas de se reorganizar a administração pública de modo global, pleno, completo, de uma vez só, não funcionam, no caso das reorganizações administrativas nos Estados Unidos. Para March e Olsen (1989, p. 96), a experiência de malogro das tentativas de reestruturação da administração pública "não é exclusiva dos Estados Unidos, mas é extensiva a vários outros países onde tais esforços (para realizar reorganizações administrativas compreensivas) têm sido feitos". Tal alegação coincide com um dos motivos arrolados por Marcelino (1989) 
para justificar o fracasso de tais reformas no Brasil. Segundo ele, uma das causas dos insucessos das tentativas de reestruturação do serviço público brasileiro é "o globalismo das iniciativas de mudança que pretendem mudar "tudo de uma vez", como se todos os problemas fossem igualmente importantes" (Marcelino, 1989, p. 115).

$\mathrm{Na}$ linha do argumento da abordagem organizacional referente ao desencontro de propósitos entre os atores institucionais que atuam na reorganização administrativa, Rezende (2002, passim, p. 123-142) desenvolve uma explicação pela qual os insucessos das tentativas de reforma da administração pública brasileira são atribuídos aos incentivos contraditórios gerados pelos objetivos de tais tentativas, que são o ajuste fiscal e a mudança institucional. Haveria divergência de finalidades entre os formuladores da reforma, no caso, a de 1995, que pretenderiam elevar a eficiência do desempenho da burocracia pública nacional, e setores relevantes do funcionalismo público, que almejariam a perpetuação do baixo desempenho burocrático como forma de conservar poder e influência no interior da máquina administrativa. Segundo a explanação do autor, em circunstâncias de baixo desempenho da burocracia pública, como ocorre na administração pública brasileira, os atores tendem a cooperar unicamente com o alcance do objetivo do ajuste fiscal, mas se recusam a cooperar com a mudança institucional, optando pela continuidade institucional, temendo perder poder, caso a instituição seja reformulada e passe a funcionar em outras bases. Isso se deve, de acordo com o aludido autor, ao fato de o ajuste fiscal requerer maior controle sobre a burocracia e a mudança institucional exigir menor controle sobre o conjunto dos servidores públicos e maiores autonomia e independência das entidades públicas, o que é interpretado pelos atores envolvidos na administração pública nacional como implicando perda de poder e influência. Por outro lado, a necessidade de maior controle sobre a burocracia, requerida pelo ajuste fiscal, é interpretada pelos atores como acarretando maior atribuição de poder aos burocratas. Como conseqüência desse fato, ocorre a cooperação parcial dos atores com o ajuste fiscal, e a não-colaboração com a finalidade da alteração institucional, o que provoca o malogro das tentativas de reestruturação.

\section{A argumentação sociológica}

$\mathrm{O}$ argumento sociológico para explicar o fracasso das tentativas de reforma da administração pública brasileira é mencionado por Graham (1968, passim, p. 60-62). O aludido autor, abordando a questão do insucesso da reforma do DASP, cita a escola sociológica como uma das vertentes do pensamento brasileiro sobre administração pública, cujos 
principais expoentes são Alberto Guerreiro Ramos e Nelson Mello e Souza (Ibidem, passim, p. 60-62). O primeiro enfatiza a necessidade de adaptação de idéias oriundas de outros países às realidades nacionais dos países nos quais serão aplicadas (Ibidem, passim, p. 60-62). Nesse caso, Ramos se refere às idéias da administração científica e ao sistema meritocrático norte-americano, nos quais os ideólogos da reforma de 1936/1938 se inspiraram. Graham (Ibidem, p. 60) escreve que Guerreiro Ramos, referindo-se ao caso do DASP, cita, como exemplo do uso de novas técnicas e idéias sem a adequada atenção ao contexto social, a experiência brasileira com o sistema de mérito transplantado dos Estados Unidos. Neste exemplo, o sistema social completamente diferente distorceu os conceitos envolvidos". Já Mello e Souza, segundo Graham (Ibidem, p. 61), considera que o principal foco de resistência à reforma administrativa no Brasil deriva das características estruturais de sociedades subdesenvolvidas. Ou seja, conforme já foi escrito na introdução deste artigo, as reformas administrativas no Brasil tentariam implantar no país valores como o mérito e a impessoalidade que não encontrariam correspondência e respaldo na prática social nacional, dificultando a efetivação das referidas reformas em nosso país. Graham (Ibidem, p. 61), referindo-se ao ponto de vista de Mello e Souza, escreve que, segundo este,

"As técnicas desenhadas para reformar a administração brasileira falharam porque elas não eram relacionadas com as necessidades administrativas do país. De acordo com sua interpretação, o sistema administrativo brasileiro é preponderantemente paternalista, dependente do ambiente político externo. Mas este sistema não pode ser considerado "patológico". Ele se torna patológico somente se julgado pela escala de valores do mundo desenvolvido. O desafio reside não tanto na rejeição do que ele denomina de valores racionalizados, mas no desenvolvimento de um senso de oportunidade pelo qual se processará uma cuidadosa e gradual superação dos problemas apresentados pelo ambiente sociopolítico" (Graham, 1968, p. 61).

A essência do argumento sociológico para explicar o fracasso das tentativas de reforma da administração pública brasileira é explanada por Mello e Souza (1994), que afirma, referindo-se à reforma do DASP de 1938, que

"Havia pouca ou nenhuma demanda nacional de criação de uma carreira na administração pública. O sistema político predominante, baseado no favoritismo e nas lealdades grupais, ainda estava forte e era, obviamente, contrário a semelhante linha de ação. As necessidades sociais relacionadas com o subemprego, o desemprego e 
mesmo com a inexistência de emprego ainda se voltavam para o setor público, com seus três níveis - municipal, estadual e federal -, como opções lógicas para obtenção de emprego, na ausência de um setor privado capaz de absorver a mão de obra disponível. A modernização de acordo com o princípio do desempenho, estabelecendo modelos de eficiência e aperfeiçoamentos marginais, provou ser um objetivo ainda inteiramente estranho aos valores políticos brasileiros e às perspectivas sociais. (...) Na ausência de necessidade social, não há aceitação social e, conseqüentemente, não há resposta social” (Mello; Souza, 1994, p. 59-60).

A argumentação de Lívia Barbosa (1996) sobre a dificuldade de implantação efetiva da meritocracia no serviço público brasileiro ainda nos dias atuais, citada na introdução do artigo, vai ao encontro das idéias de Guerreiro Ramos e Mello e Souza sobre a dificuldade de implementação de reformas administrativas no Brasil. Outro pesquisador que sintetiza bem o argumento sociológico é Kliksberg (1988), que afirma:

"Os elementos apontados permitem constatar que mudar a máquina do Estado é, provavelmente, uma das tarefas mais difíceis já enfrentadas pela sociedade contemporânea. Em face disso, a formação e a ênfase predominantes na América Latina, de caráter formalista e jurídica, parecem de uma profunda ingenuidade. Em alguns países, pensou-se que o problema seria resolvido com a sanção de novas leis que consagrassem as reformas, mas o percentual de não-aplicação das leis em nosso continente indica a distância que existe entre uma cultura jurídica, formal, e a prática real dos processos históricos" (Kliksberg,1988, p. 65-66).

\section{A reforma da administração pública como problema de ação coletiva}

A abordagem que explica o fracasso das tentativas de reforma administrativa devido ao fato de esta ser problema de ação coletiva é muito importante e será examinada. Geddes (1994) explica o insucesso das tentativas de reforma da administração pública devido ao fato de a reforma da burocracia ser um bem público, o que gera problemas de ação coletiva. Seu argumento central pode ser resumido da seguinte forma: o bem público é um tipo de bem cujo custo de exclusão é muito alto, devido ao fato de ser quase impossível evitar que quem não contribuiu para a fabricação ou para a melhoria do bem público usufrua dos benefícios gerados pela sua fabricação ou melhoria (Geddes, 1994, passim, p. 27-28). 
Um exemplo é o da iluminação pública. Uma vez instalado um poste de luz, tanto o cidadão contribuinte que paga em dia sua conta de luz quanto o inadimplente irão desfrutar dos benefícios da mesma maneira, sem que seja possível impedir que o inadimplente se beneficie da melhor iluminação. O mesmo ocorre com a reforma administrativa. Tanto os cidadãos que se mobilizarem para pressionar pela implementação da reforma quanto aqueles que se omitirem irão se beneficiar do mesmo modo das melhorias que porventura venham a ocorrer. Isso gera incentivo para o free-ride, ou "problema do carona", ou "viagem livre". Se todos irão se beneficiar da melhoria, mesmo que não se empenhem para que ela seja obtida, por que se empenhar? Então, pelo lado dos que seriam favoráveis à reforma, não há incentivos para que estes se mobilizem para que a reestruturação da administração pública ocorra efetivamente. Por outro lado, aqueles que têm a perder com a realização da reforma administrativa como, por exemplo, políticos que indicam indivíduos ligados a seus esquemas eleitorais para cargos importantes na burocracia, servidores públicos que ocupam cargos devido a apadrinhamento político, enfim, os representantes da patronagem incrustada na máquina da administração pública, permanecem mobilizados para não perder seus privilégios, fazendo, dessa forma, oposição permanente e sistemática à reforma. Desse modo, existem o problema do carona e o incentivo à desmobilização da parte daqueles que são favoráveis à reforma, e não existe o free-ride e ocorre mobilização por parte dos opositores à reforma. Dessa forma, ficam enfraquecidos os elementos favoráveis à reestruturação e fortalecidos seus adversários. A conseqüência é o malogro das tentativas de reorganização da administração pública. Para respaldar o que foi escrito, pode-se citar Geddes (1994), que afirma que:

“a realização da reforma burocrática envolve dificuldades não somente porque certos interesses a ela se opõem, mas porque, para a maioria dos que auferirão os benefícios, ela é um bem público.

O traço distintivo de um bem público é que, uma vez que o bem se torne disponível, nenhum membro de um grupo relevante pode ser facilmente excluído de usufruí-lo. Os benefícios da reforma burocrática são largamente públicos no sentido de que virtualmente todos na sociedade iriam se beneficiar de uma administração honesta e eficiente (...).

Dado que os indivíduos não podem ser excluídos de desfrutarem de bens públicos, tal como a reforma burocrática, tendo eles ajudado ou não a organizar movimentos para realizá-la, cidadãos comuns não têm incentivos para assumir riscos e despender os recursos necessários para organizar a pressão pela reforma. Esforços para realizar reformas, então, envolvem problemas de ação coletiva pelos 
quais muitos membros de uma dada sociedade ficariam em melhor situação, se todos cooperassem para que a reforma fosse realizada, mas a cooperação exigiria sacrifícios que não seriam racionais para os indivíduos fazerem. Além disso, o custo para os indivíduos é certo e pode ser tolerado no presente; benefícios são incertos e vão aparecer no futuro. Como resultado, indivíduos praticam o freeride, isto é, usufruem do benefício sem contribuir para sua realização, e, conseqüentemente, as organizações que pressionariam pela execução da reforma tendem a não se formar.

Aqueles que seriam prejudicados pela reforma não encaram impedimentos semelhantes para organizar a pressão por seus interesses. Os custos da reforma são privados e podem ser suportados desproporcionalmente por um conjunto de indivíduos que já se encontram bem organizados em partidos e sindicatos. Mudanças no recrutamento e na promoção que converteriam um sistema personalista baseado na patronagem em um sistema baseado no mérito ameaçam os servidores existentes e reduzem os recursos patrimonialistas controlados pelos políticos. Consequientemente, sindicatos de funcionários públicos, políticos e ativistas partidários têm sempre se oposto a tais mudanças"(Geddes, 1994, passim, p. 27-28).

March e Olsen (1983) corroboram a argumentação de Geddes, escrevendo que

"Participantes tentam atrelar seus próprios projetos à reorganização, para fazer deles algo que possam sustentar. (...) Isso permite uma série de interpretações negativas. Parece que, sob várias circunstâncias, mais atenção é atraída por grupos com objeções às mudanças propostas do que por aqueles grupos favoráveis a elas. Apesar de mudanças incrementais e menos visíveis não relacionadas a um esforço por uma reorganização maior freqüentemente serem bem-sucedidas, a reorganização compreensiva tende a consolidar uma oposição, ensejando uma barganha negativa no Congresso e uma oportunidade de golpear o prestígio presidencial" (March; Olsen, 1983, p. 287).

\section{A explanação política}

A abordagem política para explicar a falta de êxito das tentativas de reorganização compreensiva da administração pública americana também é feita por March e Olsen (1983, passim, p. 284-287), que apontam 
como causa adicional dos insucessos das referidas tentativas os termos do comércio político entre a Presidência da República e o Congresso dos Estados Unidos. Segundo os referidos autores, a maior parte dos planos para reorganizações administrativas não consegue sobreviver ao "comércio político". Historicamente, o padrão de barganha política sobre a organização administrativa indica que a estrutura da burocracia é mais importante para os legisladores do que para o presidente (March; Olsen, 1983, p. 285). Os presidentes americanos mais recentes têm considerado a reforma administrativa como item importante de suas agendas pessoais, mas não têm achado que seja vantajoso, politicamente, fazer barganhas com o Congresso envolvendo projetos legislativos substantivos em troca da aprovação das propostas de reforma (Ibidem, p. 285). O "comércio" político tem acontecido de outra forma. O presidente desiste de projetos de reorganização administrativa para assegurar apoio legislativo para outros assuntos, e os parlamentares desistem de fazer oposição a outros projetos em troca do bloqueio da mudança administrativa pelo Executivo, convencendo, assim, o presidente a não realizá-la (Ibidem, p. 285). A reorganização administrativa ameaça as principais prerrogativas do ofício legislativo, como o acesso às operações burocráticas e às ligações entre agências e comitês (March; Olsen, 1983, p. 285). A estrutura interna de uma agência e sua localização na estrutura departamental do governo são percebidas pelos congressistas como afetando a influência e o controle legislativos e a própria capacidade de os legisladores serem capazes de dar continuidade, no futuro, às suas carreiras políticas (Ibidem, p. 285). Um exemplo concreto da aplicação da abordagem política para explicar os insucessos das tentativas de reestruturação de nosso serviço público é o mencionado pelo pesquisador Valeriano Mendes de Almeida, da Unicamp (Universidade de Campinas). Ele nos informa o seguinte:

"Será que interessa ao sistema político que aí está o fortalecimento da burocracia estatal?" Valeriano acha que não. "Toda a lógica política do nosso presidencialismo, que se assenta na formação de amplas coalizões de governo, depende do controle dos partidos governistas sobre cargos da Administração Pública Federal", lembra ele. "À medida que esses cargos forem ocupados por servidores de carreira, as bases do clientelismo serão mortalmente atingidas. Assim, não é preciso muita imaginação para avaliar os obstáculos que ainda se oporão à reforma" (Bressan, apud Lamounier; Figueiredo, 2002, p. 393).

Ou seja, os próprios políticos brasileiros, atores institucionais que operam no contexto político-administrativo nacional, resistem à realização da reforma do Estado, por considerarem que vão perder poder, se ela 
for implementada, na medida em que não mais indicarão os titulares de cargos importantes na Administração Pública Federal, que passarão a ser preenchidos por burocratas de carreira, concursados e selecionados por mérito.

Geddes (1994) também faz uso do argumento político para explicar os fracassos das tentativas de reforma da administração pública brasileira. Ela escreve que:

"O estudo de caso do Brasil mostra a persistência dos interesses políticos opostos à reforma burocrática e suas vinculações com o sistema político democrático (...).

Este modelo demonstra que, quando a patronagem é distribuída desigualmente entre os maiores partidos na legislatura (...), os legisladores dos partidos majoritários vão votar pelas reformas somente em circunstâncias extraordinárias. Conseqüentemente, as reformas vão ocorrer muito raramente.

Se a patronagem fosse distribuída igualmente entre os partidos maiores, entretanto, as reformas poderiam ocorrer mais facilmente. O Brasil nunca experimentou igualdade entre os partidos, e reformas universais nunca foram aprovadas no Legislativo" (Geddes, 1994, p. 20-21).

Analisando especificamente a influência do sistema eleitoral sobre o insucesso das tentativas de reforma administrativa, a mesma autora escreve que "o sistema brasileiro de representação proporcional de lista aberta para eleição da Câmara dos Deputados forneceu aos parlamentares do PSD e do PTB - os partidos com maior acesso histórico à patronagem - recursos ainda mais poderosos para se oporem à reforma. Por isso não surpreende o fato de que as reformas não passaram em 1946 e 1964" (Ibidem, p. 115).

A mencionada autora resume a essência da explicação política para o malogro das tentativas de reforma administrativa da seguinte maneira:

"A competência administrativa é uma forma de bem coletivo especialmente custosa para muitos políticos porque (...) políticos em sistemas não reformados confiam no acesso aos recursos do Estado para construir bases de apoio, e a reforma administrativa ameaça este acesso. Reformas efetivas estabelecendo o mérito como critério para emprego, competição de preço como critério para obter contratos, e regras impessoais para determinar quem recebe benefícios do governo, iriam privar os políticos de importantes recursos" (Geddes, 1994, p. 42). 
Em suma, as reformas da administração pública não prosperariam

porque "os mesmos recursos necessários para aumentar a capacidade do Estado poderiam ser usados pelos políticos, alternativamente, para elevar suas chances de reeleição" (Ibidem, p. 98).

Esse é o dilema no qual, segundo a referida autora, estão inseridos os políticos da América Latina no que tange à construção da capacidade estatal na aludida região, qual seja, despender os recursos públicos para melhorar o desempenho da burocracia, ou utilizá-los com a finalidade de assegurar sua sobrevivência política. Até o momento, os políticos latinoamericanos têm optado pela segunda alternativa.

\section{Notas}

1 Externalidades em rede: Corresponderiam à idéia de "efeitos de coordenação", que "ocorreriam quando os benefícios que um indivíduo recebe de uma atividade particular aumentassem à medida que outros adotassem a mesma opção. (...) $\mathrm{O}$ aumento do uso de uma tecnologia encoraja o investimento na infra-estrutura associada, o que, por sua vez, atrai mais usuários para a tecnologia"(Pierson, 2000, p. 254). Tanto esse conceito quanto o que é a seguir enunciado são, originalmente, referentes à questão da tecnologia na economia, mas tanto North (1990) quanto Pierson (2000) os aplicam à análise de questões institucionais.

2 Processo de aprendizado das organizações: Segundo Pierson, "o conhecimento adquirido na operação de sistemas complexos também conduz a retornos crescentes pelo uso continuado. Com a repetição, indivíduos aprendem como usar os produtos de modo mais efetivo, e suas experiências são no sentido de afastar inovações posteriores no produto ou em atividades relacionadas"(Pierson, 2000, p. 254).

3 Modelos subjetivos de percepção das questões públicas: Corresponderiam, segundo Pierson (2000, p. 260), à maneira pela qual os atores que operam em contextos sociais altamente complexos e opacos filtram e interpretam as informações que recebem. 
Barbosa, L. Meritocracia à brasileira: o que é desempenho no Brasil? Revista do Serviço Público. Brasília, ano 47, v. 120, n. 3, set./dez. 1996.

Bressan, S. A era FHC - um balanço. In: Lamounier, B.; FigueIredo, R. São Paulo: Cultura Editores Associados, 2002.

Cohen, M.; March, J.; Olsen, J. A garbage can model of organizational choice, Administrative Science Quartely, 17, p. 1-25.

GedDEs, B. Politician's dilemmas: building State capacity in Latin America. Berkeley: University of California, 1994.

Goodin. R.; Kingerman, H. A new handbook of political science. Oxford: Oxford University Press, 1998.

Graham, L. Civil service reform in Brazil. Austin: University of Texas at Austin, 1968.

Kliksberg, B. A gerência na década de 90. Revista de Administração Pública. Rio de Janeiro, v. 22, n. 1, jan./mar. 1988.

LiMA JÚNIOR, O. B. As reformas administrativas no Brasil: modelos, sucessos e fracassos. Revista do Serviço Público. Brasília, n. 2, p. 5-31, abr./jun. 1998.

MARCELINo, G. Administração pública brasileira: evolução, situação atual e perspectivas futuras. Revista do Serviço Público. Brasília, v. 17, n. 2, p. 105-115, set./dez. 1989.

March, J.; OlsEn, J. Organizing political life: what administrative reorganization tell us about government. American Political Science Review, v. 77, n. 2, p. 281-296, June 1983.

The New Institucionalism: organizational factors in political life. American Political Science Review, 1984.

York: Free Press, 1989.

Rediscovering institutions: the organizational basis of politics. New

NoRTH, D. Custos de transação, instituições e desempenho econômico. Rio de Janeiro: Instituto Liberal, 1992.

Institutions, institutional change and economic performance.

Cambridge: Cambridge University Press, 1990.

OlLaik, L. Fundamentos e etapas da reforma administrativa no Brasil de 1995 a 1998. 1999. Tese (Mestrado) - Universidade de Brasília, Brasília.

PIERSON, P. Increasing returns, path dependance and the study of politics. American Political Science Review, v. 94, n. 2, p. 251-267, June 2000.

REZENDE, F. Por que reformas administrativas falham? Revista Brasileira de Ciências Sociais. São Paulo, v. 17, n. 50, p. 123-142, out. 2002.

SANtos, L. A reforma administrativa no contexto da democracia. Brasília: DIAP, 1997.

SIEGEL, G. The vicissitudes of governamental reform in Brasil: a study of the DASP. Michigan: Ann Arbor, 1986.

Souza, N. M. Reforma administrativa no Brasil: um debate interminável. Revista de Administração Pública. Rio de Janeiro, v. 28, n. 1, p. 54-70, jan./mar. 1994.

WAHRLICH, B. A reforma administrativa da era de Vargas. Rio de Janeiro: Editora FGV, 1983.

A reforma administrativa no Brasil: experiência anterior, situação 


\section{Levantamento teórico sobre as causas dos insucessos das tentativas de reforma administrativa}

Carlos Frederico Alverga

$\mathrm{O}$ presente artigo tem como objetivo identificar e analisar os principais motivos apontados na literatura pertinente como causadores dos sucessivos e reiterados fracassos das tentativas de reforma da administração pública brasileira. As referidas tentativas foram empreendidas em 1938, quando da criação do Departamento Administrativo do Serviço Público (DASP), durante a ditadura do Estado Novo; em 1963, quando Ernani do Amaral Peixoto foi designado ministro extraordinário para a Reforma Administrativa; em 1967, quando da edição do Decreto-Lei n ${ }^{\circ}$ 200, de 25/2/1967 e, também, em 1986, 1990 e 1995, nos Governos Sarney, Collor e Cardoso, respectivamente. Todas elas visavam, basicamente, a implantar a meritocracia na administração pública brasileira. Segundo os autores consultados, essas tentativas foram malsucedidas devido aos seguintes fatores: a questão da dependência da trajetória, as características das organizações que dificultam a ocorrência de alterações institucionais, os elementos de natureza sociológica, o fato de a reforma administrativa ser bem público sujeito a problemas de ação coletiva e, finalmente, as peculiaridades do sistema político brasileiro.

\section{Examen teórico de las causas del fracaso de las tentativas de reforma administrativa \\ Carlos Frederico Alverga}

El presente artículo consiste en una análisis de los principales motivos apuntados por la literatura pertinente como causadores de los sucesivos fracassos de lãs tentativas de reestruturación de la administración pública brasilenã. Lãs referidas tentativas fuerán intentadas em 1938, cuando de la creación de lo Departamento Administrativo do Serviço Público (DASP), em la dictadura de lo Estado Nuevo; em 1963, cuando Amaral Peixoto fuera nombrado ministro extraordinário para la Reforma Administrativa; em 1967, cuando de la edición de lo Decreto-Ley número 200, de 25/2/1967, e también en 1986, 1990 e 1995, em los Gobiernos Sarney, Collor e Cardoso, respectivamente. Todas elas miraván establecer el sistema de merecimiento em la administración pública brasilenã e, em conformidad com los autores consultados, fracassarán. Los fatores apuntados como causas de los mencionados malogros fuéran la cuestión de la dependência de la trayectoria, características de las organizaciones, lãs cuales dificultán lãs alteraciones institucionales, los fatores sociológicos, lo hecho de la reforma administrativa ser um bien público sujeto a problemas de acción coletiva e las peculiaridades de lo sistema político brasileño.

\section{Theoretical survey on the failure causes of administrative reform attempts Carlos Frederico Alverga}

The article aims to identify and analyze the main causes pointed by the literature as the reasons of the succeeding failures of the attempts to reform the Brazilian public administration. These attempts were carried out in 1938, when the Administrative Department of the Public Service was created, during Vargas's dictatorship; in 1963, when Ernani do Amaral Peixoto was nominated extraordinary minister of State for Administrative Reform; in 1967, when the Decree-Law number 200 was edited, and, also, in 1986, 1990
Revista do

Serviço

Público

Ano 54

Número 3

Jul-Set 2003

Carlos Frederico

Alverga é

mestre em

Ciência Política pela UnB.

Contato: rubino68@ ig.com.br 
and 1995, in the governments of Sarney, Collor and Cardoso, respectively. All these attempts of public administration reform in Brazil intended, basically, to establish the merit system in Brazilian civil service. According to the consulted authors, all these attempts failed. The factors that explain these failures are the following: path dependence; organizations' features which difficult institutional changes; elements of sociological nature; the fact that administrative reform is a public good exposed to collective action problems; characteristics of Brazilian political system. 